\title{
Block Copolymer Sequence Inversion through Photoiniferter Polymerization
}

Charles P. Easterling, ${ }^{\dagger}{ }^{\dagger}$ Yening Xia, ${ }^{\dagger}$ Junpeng Zhao, ${ }^{\mathbb{}}$ Gail E. Fanucci ${ }^{\dagger *}$ and Brent S. Sumerlin ${ }^{\dagger *}$

$\uparrow$ George \& Josephine Butler Polymer Research Laboratory, Center for Macromolecular Science \& Engineering, Department of Chemistry, University of Florida, P.O. Box 117200, Gainesville, Florida 32611-7200, United States

$¥$ Center for Integrated Nanotechnologies, Sandia National Laboratories, Albuquerque, New Mexico 87185, United States

${ }^{\pi}$ Faculty of Materials Science and Engineering, South China University of Technology, Guangzhou 510640, People's Republic of China 


\section{Table of Contents}

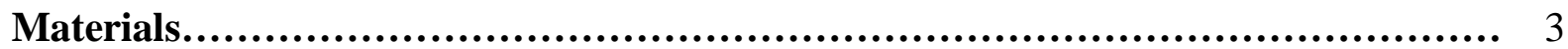

Instrumentation........................................................................ 3

Nuclear Magnetic Resonance Spectroscopy .................................... 3

Gel Permeation Chromatography................................................ 3

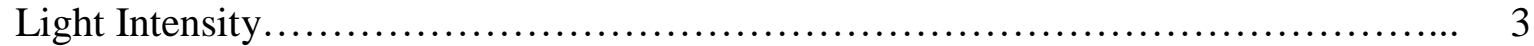

UV-Vis Spectroscopy................................................................................... 3

Synthetic Procedures..................................................................................................... 4-6

Ethyl 2-((ethoxycarbonothioyl)thio)-2-methylpropanoate............................................... 4

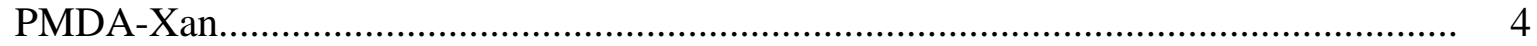

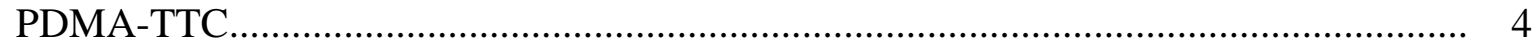

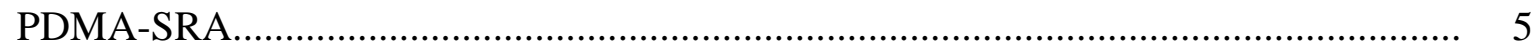

General procedure for photoiniferter-mediated chain extensions...................................... 5

General procedure for thermal RAFT-mediated chain extensions................................... $5-6$

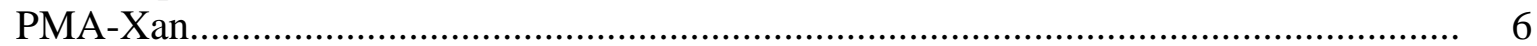

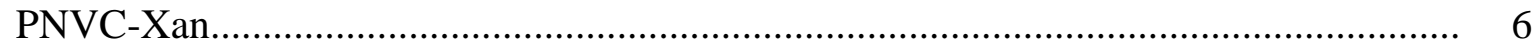

Supplemental Figures..................................................................................................................... 7-13

Figure S1. ${ }^{1} \mathrm{H}$ NMR of ethyl 2-((ethoxycarbonothioyl)thio)-2-methylpropanoate........... 7

Figure S2. Kinetic studies of PDMA-TTC chain extension with MMA......................... 8

Figure S3. GPC chromatogram of PDMA- $b$-PMMA synthesized using a trithiocarbonate iniferter.

Figure S4. GPC chromatogram of PDMA- $b$-PMMA synthesized using a trithiocarbonate iniferter in the presence of Eosin $\mathrm{Y}$

Figure S5. Deconvoluted GPC chromatogram of PDMA- $b$-PMMA (Xan).

Figure S6. Kinetic studies of PDMA-Xan chain extensions with MMA.

Figure S7. Comparison of PDMA-Xan and PDMA-TTC mediated chain extensions with MMA

Figure S8. Thermal RAFT chain extension of PDMA-Xan with MMA.

Figure S9. GPC chromatograms of PDMA- $b$-PMMA (Xan) targeting various MMA degrees of polymerization.

Figure S10. Small molecule photolysis study comparing the relative photolysis rates of acrylic and methacrylic chain ends

Figure S11. GPC chromatograms reveling an effect of initial monomer concentration on asymmetric chain growth when targeting a higher MMA degree of polymerization.

Figure S12. Deconvoluted GPC chromatogram of PDMA- $b$-PMMA (SRA) .................. 14 


\section{Materials}

All chemicals were used as received unless otherwise noted. N,N-Dimethylacrylamide (DMA, Aldrich, 99\%), methyl acrylate (MA, Sigma-Aldrich, 99\%) and methyl methacrylate (MMA, Sigma-Aldrich, 99\%) were passed through basic alumina to remove inhibitors and acidic impurities prior to polymerization. Azobisisobutyronitrile (AIBN, Sigma-Aldrich, 98\%) was recrystallized from ethanol and dried in vacuo prior to use. 1,4-Dioxane (ACS, Fisher Scientific) was passed through basic alumina to remove inhibitors and peroxide impurities. Ethyl 2((ethoxycarbonothioyl)thio)propanoate and 2-(dodecylthiocarbonothioylthio)-2-methylpropionic acid (DMP) were synthesized according to previous reports. ${ }^{1,2}$ Ethyl 2-bromoisobutyrate (>98\%) was purchased from Alfa Aesar. Potassium ethyl xanthogenate (96\%) and $\mathrm{N}$-vinylcarbazole (NVC, 98\%) was purchased from Sigma-Aldrich. Dimethyl sulfoxide (DMSO, ACS), tetrahydrofuran (THF, ACS), acetone (ACS), hexanes (ACS), ethyl acetate (ACS) toluene (ACS) were purchased from Fischer Scientific.

\section{Instrumentation}

Nuclear Magnetic Resonance (NMR) Spectroscopy. ${ }^{1} \mathrm{H}$ NMR spectra were recorded on a Varian Innova2 $500 \mathrm{MHz}$ NMR spectrometer using the residual solvent signal as a reference.

Size Exclusion Chromatography (SEC). Molecular weights and molecular weight distributions were determined via multi-angle laser light scattering gel permeation chromatography (MALSGPC) in $N, N$-dimethylacetamide (DMAc) with $50 \mathrm{mM} \mathrm{LiCl}$ at $50{ }^{\circ} \mathrm{C}$ and a flow rate of $1.0 \mathrm{~mL} / \mathrm{min}$ (Agilent isocratic pump, degasser, and autosampler; ViscoGel I-series $10 \mu \mathrm{m}$ guard column and two ViscoGel I-series G3078 mixed bed columns, with molecular weight ranges $0-20 \times 10^{3}$ and $0-10 \times 10^{6} \mathrm{~g} / \mathrm{mol}$, respectively). Detection consisted of a Wyatt Optilab T-rEX refractive index detector operating at $658 \mathrm{~nm}$ and a Wyatt miniDAWN Treos light scattering detector operating at $659 \mathrm{~nm}$. Absolute molecular weights and polydispersities were calculated using Wyatt ASTRA software.

Light Intensity was measured with General UV513AB Digital UV AB Light Meter calibrated at $365 \mathrm{~nm}$.

UV-Vis Spectroscopy. All measurements were performed on a Molecular Devices SpectraMax 2 M2 Multimode Microplate Reader at $25^{\circ} \mathrm{C}$. Absorbance measurements were conducted with 150 $\mu \mathrm{L}$ of sample on clear 96-well microplates (Greiner). PDMA macro-CTAs were dissolved in DMSO at a concentration of $1 \mathrm{mg} / \mathrm{mL}$ to monitor $\pi \rightarrow \pi^{*}$ transitions. Detection of $\mathrm{n} \rightarrow \pi^{*}$ transitions required higher polymer concentrations $(50 \mathrm{mg} / \mathrm{mL})$. 


\section{Synthetic Procedures}

\section{Ethyl 2-((ethoxycarbonothioyl)thio)-2-methylpropanoate}

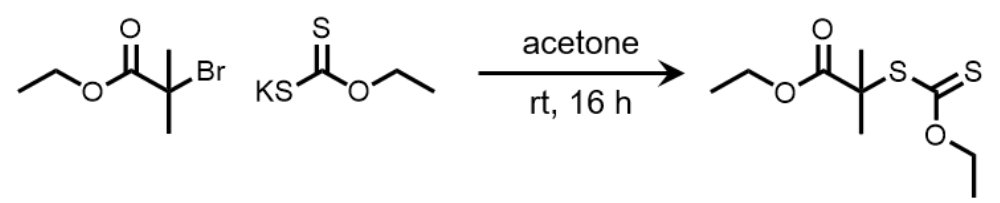

Potassium ethyl xanthogenate $(247 \mathrm{mg}, 1.54 \mathrm{mmol})$ was dissolved in acetone $(1.00 \mathrm{~mL})$ prior to adding ethyl 2-bromoisobutyrate $(250 \mathrm{mg}, 1.28 \mathrm{mmol})$. After $16 \mathrm{~h}$, the solution was filtered through a short silica plug to remove $\mathrm{KBr}$ and residual potassium ethyl xanthogenate followed by further purification via column chromatography (9:1 Hex:EtOAc). Yield: $209 \mathrm{mg}(69 \%)$. ${ }^{1} \mathrm{H} \mathrm{NMR}$ (500 MHz, $\left.\mathrm{CDCl}_{3}\right): \delta(\mathrm{ppm}) 4.59(\mathrm{~m}, 2 \mathrm{H}), 4.19(\mathrm{~m}, 2 \mathrm{H}), 1.61(\mathrm{~s}, 6 \mathrm{H}), 1.39(\mathrm{t}, 3 \mathrm{H}), 1.27(\mathrm{t}, 3 \mathrm{H})$.

\section{PDMA-Xan}

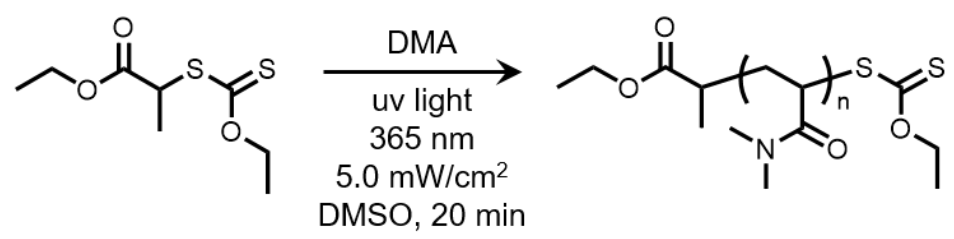

DMA (1.00 g, mmol) and ethyl 2-((ethoxycarbonothioyl)thio)propanoate (56 mg, $2.52 \times 10^{-1} \mathrm{mmol}$ mmol) were dissolved in DMSO $(20 \mathrm{~mL})$ and transferred to a $25 \mathrm{~mL}$ Schlenk flask. The reaction flask was wrapped in aluminum foil to prevent premature photolysis and then sparged with argon for $20 \mathrm{~min}$. The reaction vessel was positioned $2 \mathrm{~cm}$ from the UV light source $\left(5.0 \mathrm{~mW} / \mathrm{cm}^{2}\right)$. The reaction solution was then irradiated for a total of $20 \mathrm{~min}$ while nitrogen gas was blown across the surface of the lamp to prevent temperature fluctuations. The reaction was quenched by turning off the UV light and was left unperturbed for $1 \mathrm{~h}$ to allow for thiyl radical termination prior to exposure to atmospheric oxygen. The product was purified by dialysis (Spectra/Por 3.5 kD MWCO) of the reaction solution against acetone, followed by drying under reduced pressure. $\left(M_{\mathrm{n}}\right.$ GPC MALS $=4.84$ $\left.\mathrm{kg} \mathrm{mol}^{-1}, \emptyset=1.16\right)$.

\section{PDMA-TTC}

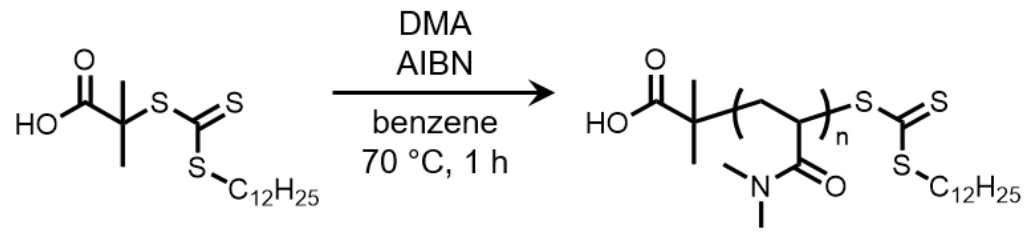

DMA (7.70 g, $77.7 \mathrm{mmol}$ ), DMP (378 mg, $1.04 \mathrm{mmol}$ ) and AIBN (34 mg, $2.07 \times 10^{-1} \mathrm{mmol}$ ) were dissolved in benzene $\left(39 \mathrm{~mL}, 2 \mathrm{M}[\mathrm{DMA}]_{0}\right)$ and transferred to a $50 \mathrm{~mL}$ Schlenk flask. The reaction solution was purged with argon for 45 min while stirring. The reaction flask was then submerged in a preheated oil bath set to $70{ }^{\circ} \mathrm{C}$ and was allowed to react for $1 \mathrm{~h}$ prior to quenching upon exposure to atmospheric oxygen. The product was purified by precipitation into cold hexanes, followed by drying under reduced pressure. $\left(M_{\mathrm{n} \text { GPC MALS }}=8.18 \mathrm{~kg} \mathrm{~mol}^{-1}, Ð=1.03\right)$. 


\section{PDMA-SRA}

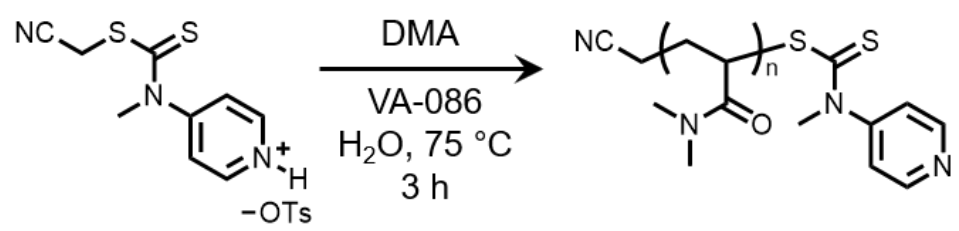

DMA (2.71 g, $27.3 \mathrm{mmol}, 100$ equiv), VA-086 (7.9 mg, $2.73 \times 10^{-1} \mathrm{mmol}, 0.1$ equiv) and cyanomethyl methyl(4-pyridyl)carbamodithioate $\left(61 \mathrm{mg}, 2.73 \times 10^{-1} \mathrm{mmol}, 1\right.$ equiv) were dissolved in water $(9.1 \mathrm{~mL})$ and transferred to a $10 \mathrm{~mL}$ Schlenk flask. $p$-Toluenesulfonic acid (52 $\mathrm{mg}, 2.73 \times 10^{-1} \mathrm{mmol}, 1$ equiv) was then added to the reaction vessel and the mixture was purged with argon for $20 \mathrm{~min}$. The reaction vessel was then submerged in a preheated oil bath set to 70 ${ }^{\circ} \mathrm{C}$ and was allowed to react for $3 \mathrm{~h}$ prior to quenching upon exposure to atmospheric oxygen. Note: $p$-toluenesulfonic acid did not fully dissolve until heated. The product was purified by dialysis (Spectra/Por $3.5 \mathrm{kD} \mathrm{MWCO}$ ) of the reaction solution against deionized water, followed by lyophilization $\left(M_{\mathrm{n} \text { GPC MALS }}=9.68 \mathrm{~kg} \mathrm{~mol}^{-1}, Ð=1.06\right)$. PDMA-SRA chain ends were deprotonated by passing the polymer solution $(50 \mathrm{mg} / \mathrm{mL}$ in DCM) through a column of sodium carbonate, followed by precipitation against hexanes and subsequent drying under vacuum.

\section{General procedure for photoiniferter-mediated chain extensions}

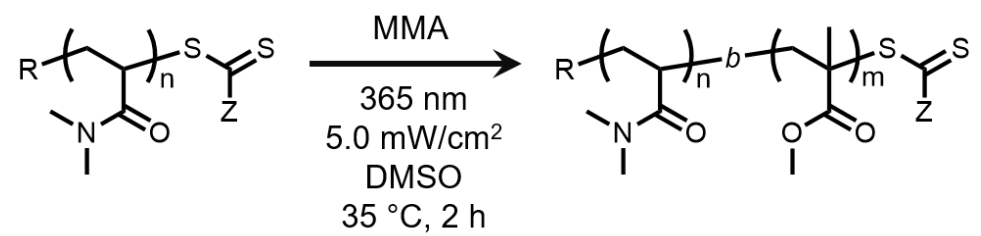

PDMA macro-CTA (1 equiv), MMA (300 equiv), and DMSO were dissolved, reaching an initial MMA monomer concentration of $1.5 \mathrm{M}$ and subsequently transferred to a $10 \mathrm{~mL}$ Schlenk flask. The reaction solution was purged with argon for $20 \mathrm{~min}$ while stirring prior to exposure to UV light for predetermined reaction times. Monomer conversion was determined by comparing O$\underline{\mathrm{C}}_{3}$ resonances with olefinic MMA resonances by ${ }^{1} \mathrm{H}$ NMR spectroscopy. Samples were purified by dialysis (Spectra/Por $3.5 \mathrm{kDa} \mathrm{MWCO}$ ) against acetone, followed by drying under reduced pressure.

\section{General procedure for thermal RAFT-mediated chain extensions}

Reaction conditions were designed to mimic photoiniferter-mediated chain extensions. MacroCTA (1 equiv), MMA (300 equiv), AIBN (0.1 equiv) and toluene were dissolved, reaching an initial MMA monomer concentration of $1.5 \mathrm{M}$ and subsequently transferred to a $10 \mathrm{~mL}$ Schlenk flask. The reaction solution was purged with argon for $20 \mathrm{~min}$ while stirring prior to being submerged in a preheated oil bath set to $70{ }^{\circ} \mathrm{C}$ for $16 \mathrm{~h}$. Monomer conversion was determined by comparing $\mathrm{O}-\mathrm{C}_{3} 3$ resonances with olefinic MMA resonances by ${ }^{1} \mathrm{H}$ NMR spectroscopy. Samples were purified by dialysis (Spectra/Por $3.5 \mathrm{kDa} \mathrm{MWCO}$ ) against acetone, followed by drying under reduced pressure. 


\section{PMA-Xan}<smiles>CCOC(=O)C(C)SC(=S)OCC</smiles>

The following procedure was performed according to previous method. ${ }^{3} \mathrm{MA}(5.00 \mathrm{~g}, 58.1 \mathrm{mmol})$, ethyl 2-((ethoxycarbonothioyl)thio)propanoate $\left(81 \mathrm{mg}, 3.87 \times 10^{-1} \mathrm{mmol}\right)$ and AIBN $(13 \mathrm{mg}, 7.74$ $\left.\times 10^{-2} \mathrm{mmol}\right)$ were dissolved and transferred to a $10 \mathrm{~mL}$ Schlenk flask. The reaction solution was purged with argon for $20 \mathrm{~min}$ while stirring. The reaction flask was then submerged in a preheated oil bath set to $60{ }^{\circ} \mathrm{C}$ and was allowed to react for $1 \mathrm{~h}$ prior to quenching upon exposure to atmospheric oxygen. The product was purified by dialysis (Spectra/Por 3.5 kD MWCO) of the reaction solution against acetone, followed by drying under reduced pressure. $\left(M_{\mathrm{n}}\right.$ GPC MALS $=18.1$ $\left.\mathrm{kg} \mathrm{mol}^{-1}, Ð=1.17\right)$

\section{PNVC-Xan}<smiles>CCOC(=O)C(C)SC(=S)OCC</smiles>

NVC (1.00 g, $5.17 \mathrm{mmol})$, ethyl 2-((ethoxycarbonothioyl)thio)propanoate $\left(23 \mathrm{mg}, 1.03 \times 10^{-1}\right.$ mmol) and AIBN (3.4 mg, $\left.2.07 \times 10^{-2} \mathrm{mmol}\right)$ were dissolved in 1,4-dioxane $(2.59 \mathrm{~mL}, 2 \mathrm{M}$ $\left.[\mathrm{NVC}]_{0}\right)$ and transferred to a $10 \mathrm{~mL}$ Schlenk flask. The reaction solution was purged with argon for 20 min while stirring. The reaction flask was then submerged in a preheated oil bath set to 70 ${ }^{\circ} \mathrm{C}$ and was allowed to react for $16 \mathrm{~h}$ prior to quenching upon exposure to atmospheric oxygen. The product was purified by dialysis (Spectra/Por $3.5 \mathrm{kD} \mathrm{MWCO}$ ) of the reaction solution against THF, followed by drying under reduced pressure. $\left(M_{\mathrm{n} \text { GPC MALS }}=10,760 \mathrm{~g} / \mathrm{mol}, \nexists=1.07\right)$. 


\section{Supplemental Figures}

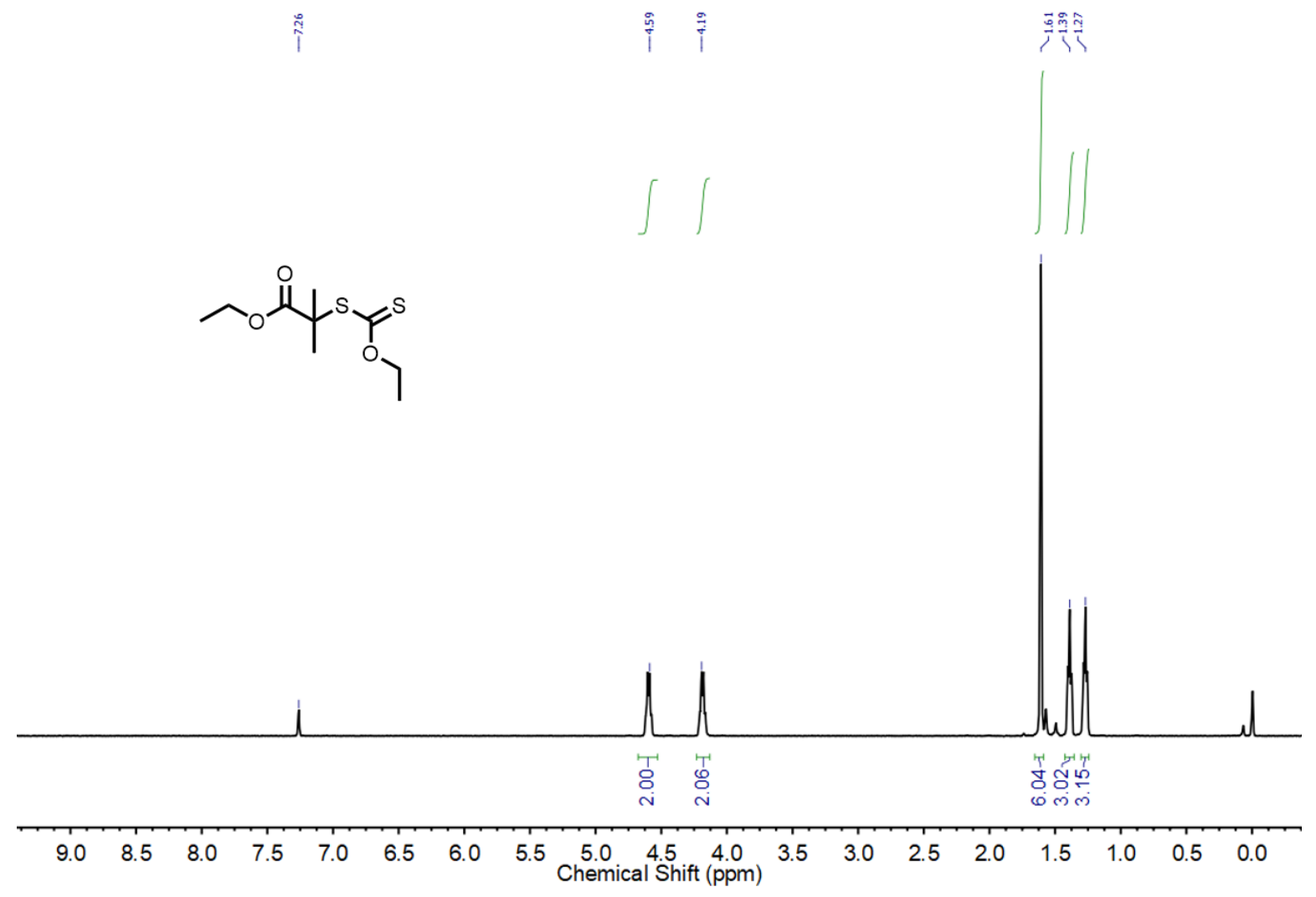

Figure S1. ${ }^{1} \mathrm{H}$ NMR spectrum of ethyl 2-((ethoxycarbonothioyl)thio)-2-methylpropanoate in $\mathrm{CDCl}_{3}$ at $25^{\circ} \mathrm{C}$. 

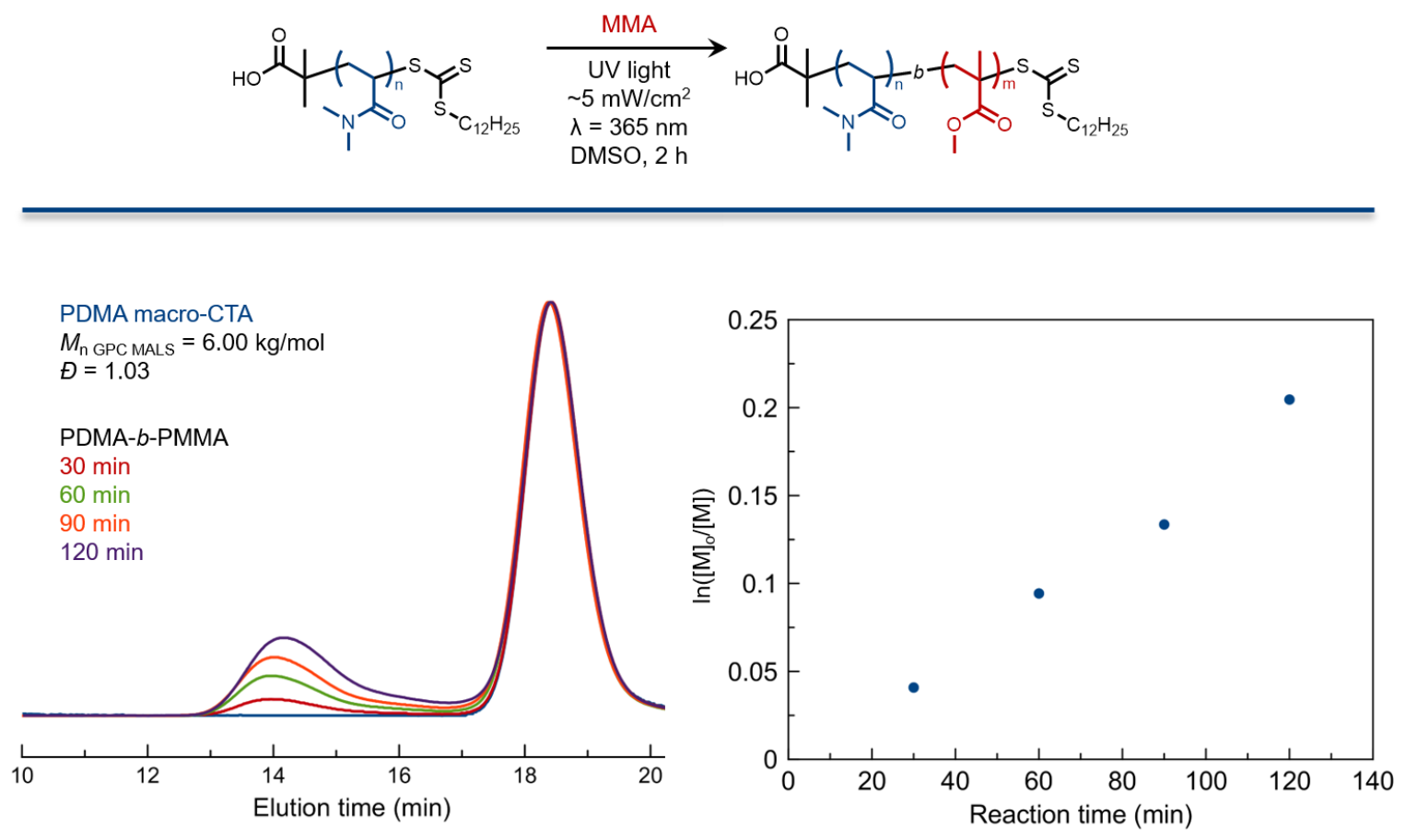

Figure S2. Kinetic studies of PDMA-TTC chain extension with MMA. 


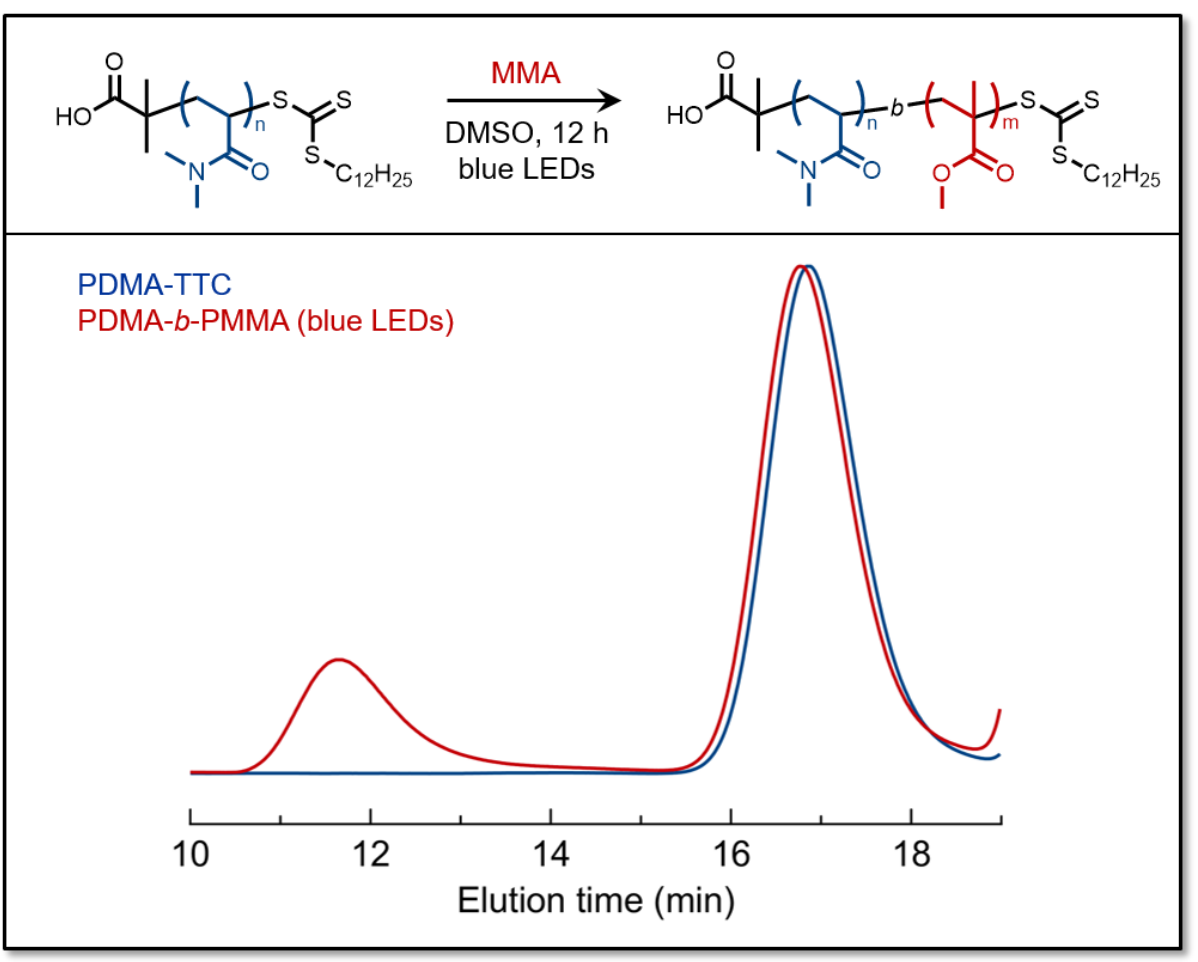

Figure S3. GPC chromatogram of PDMA- $b$-PMMA synthesized using a trithiocarbonate iniferter.

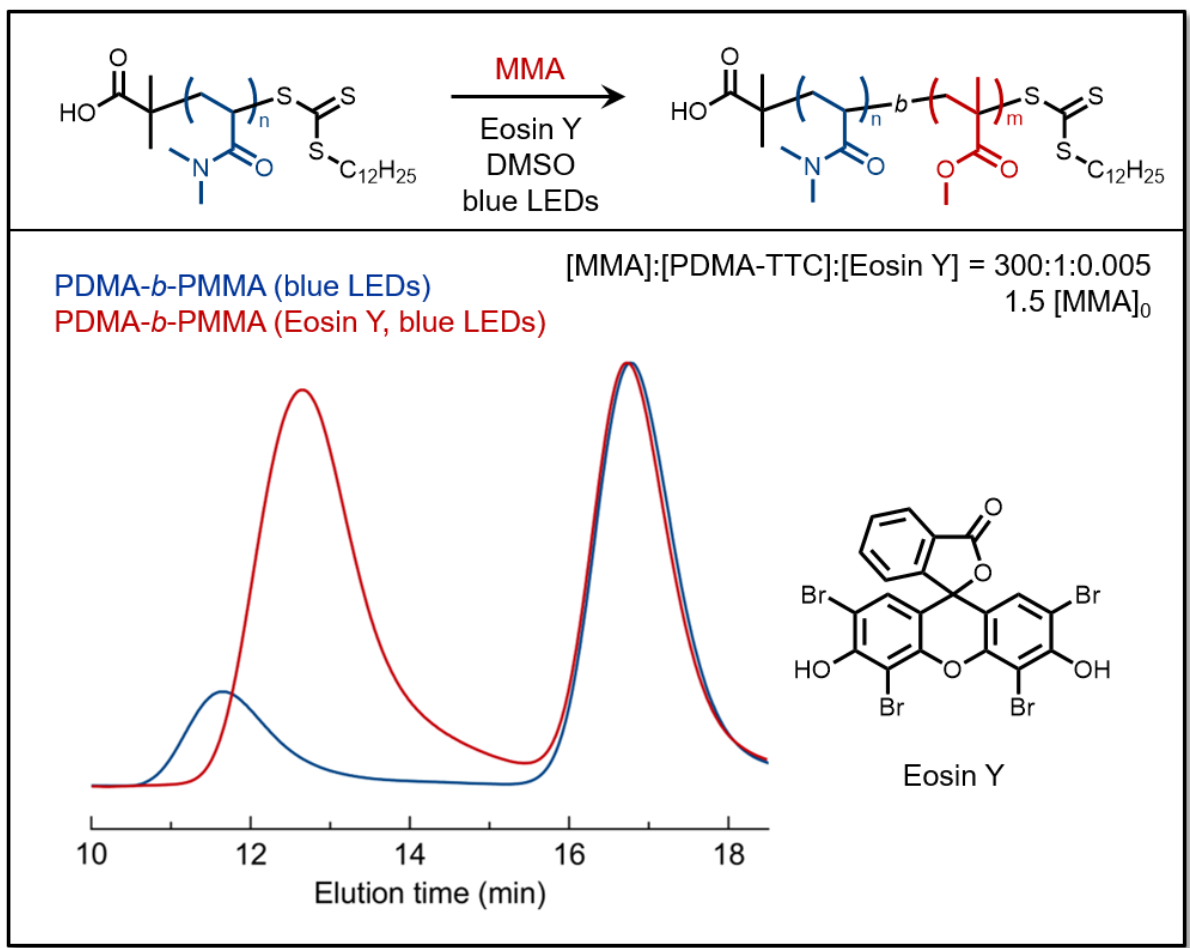

Figure S4. GPC chromatogram of PDMA- $b$-PMMA synthesized using a trithiocarbonate iniferter in the presence of Eosin Y. 

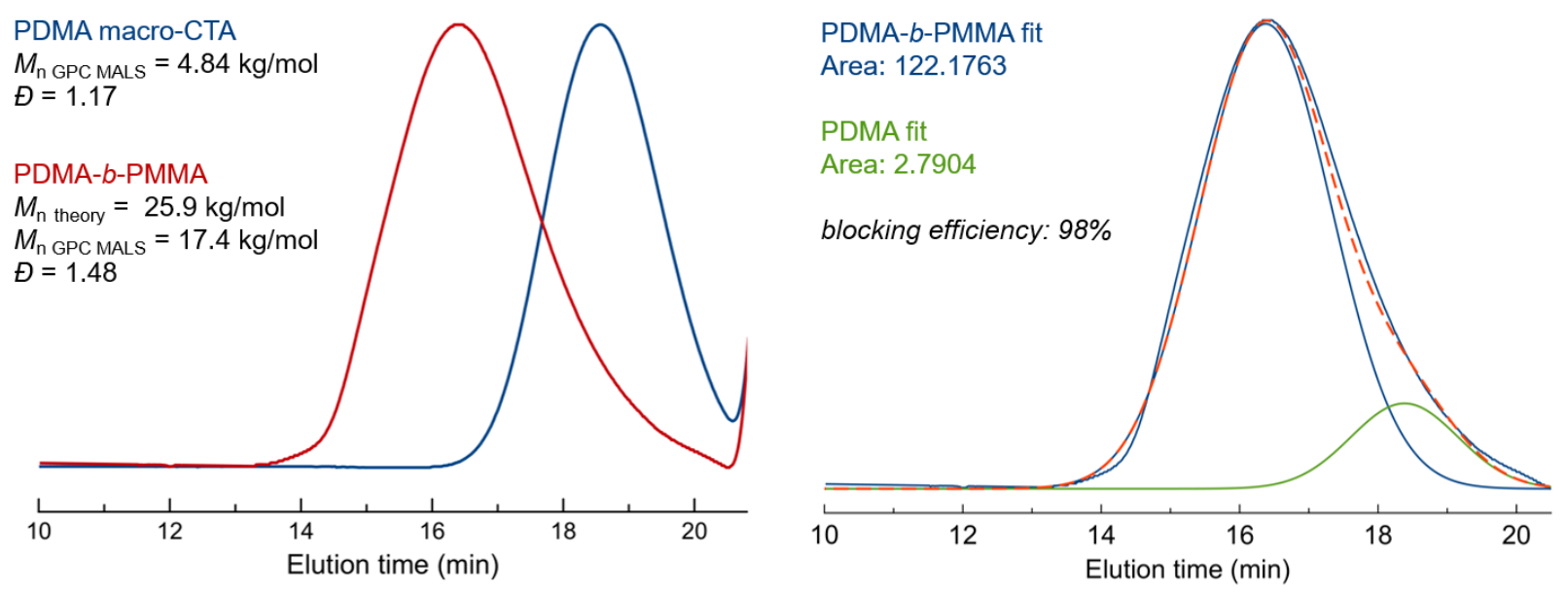

Figure S5. Deconvoluted GPC chromatogram of PDMA- $b$-PMMA (Xan).
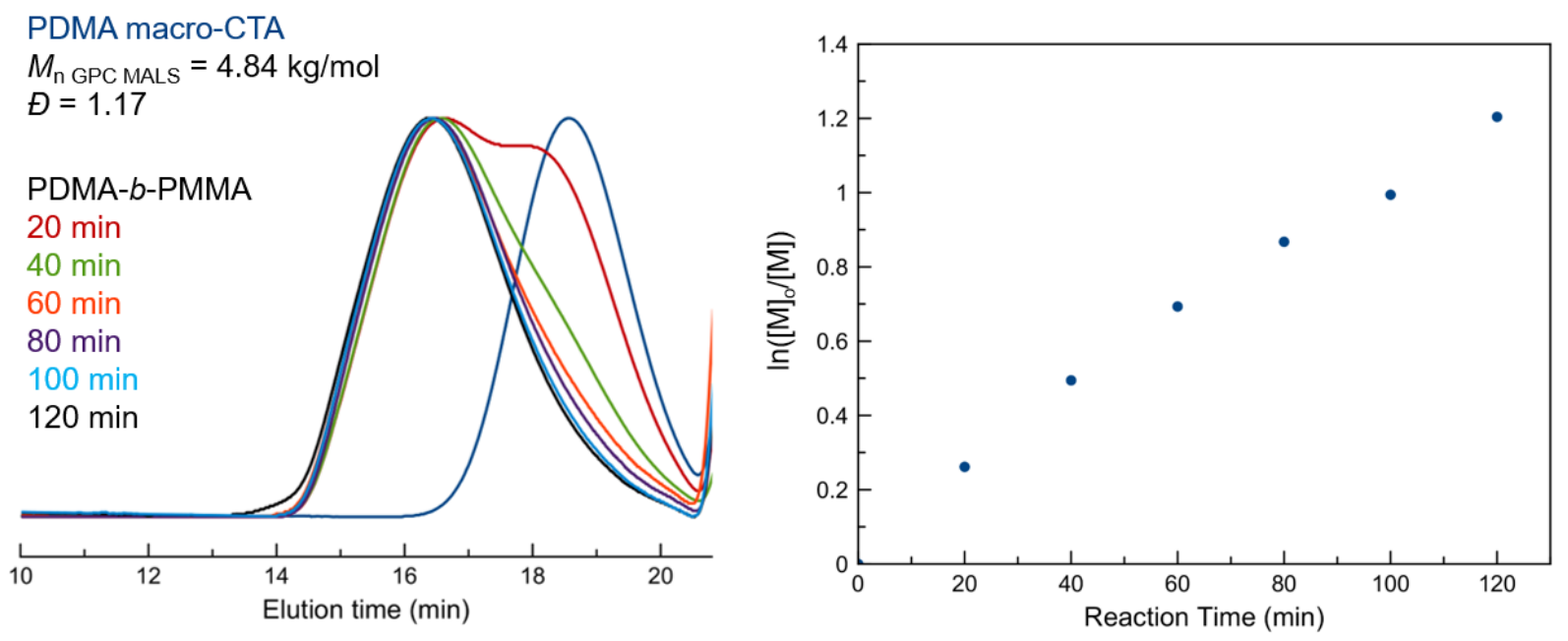

Figure S6. Kinetic studies of PDMA-Xan chain extensions with MMA. 


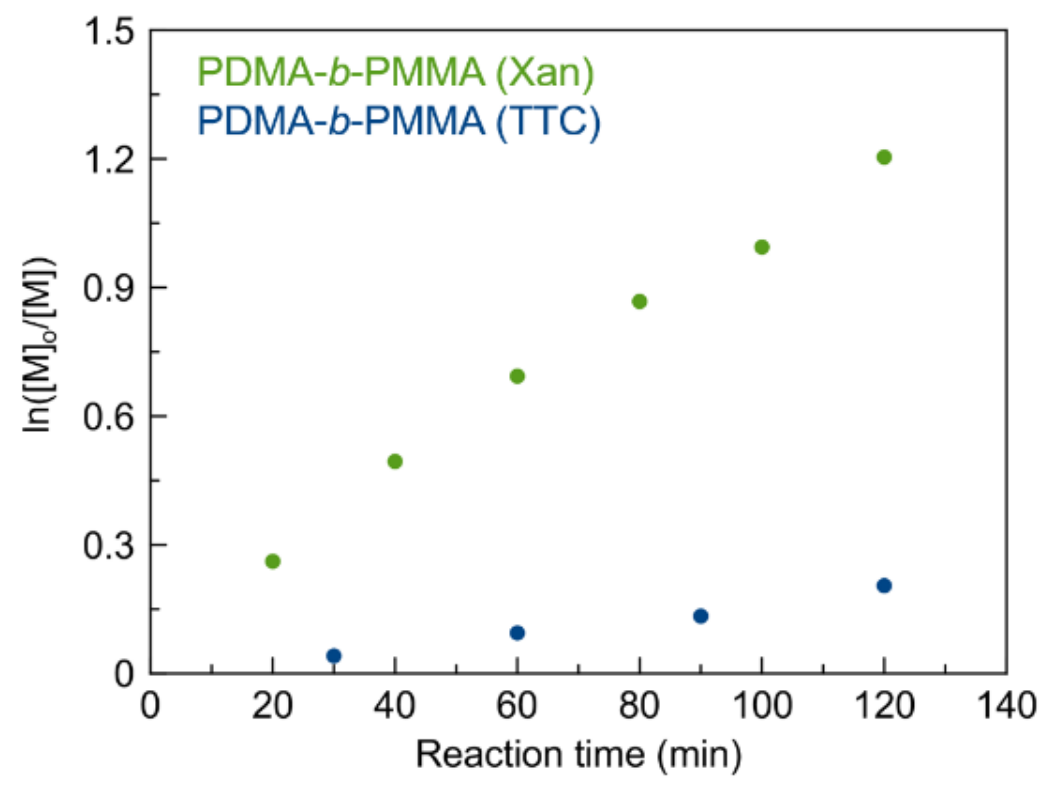

Figure S7. Comparison of PDMA-Xan and PDMA-TTC mediated chain extensions with MMA.

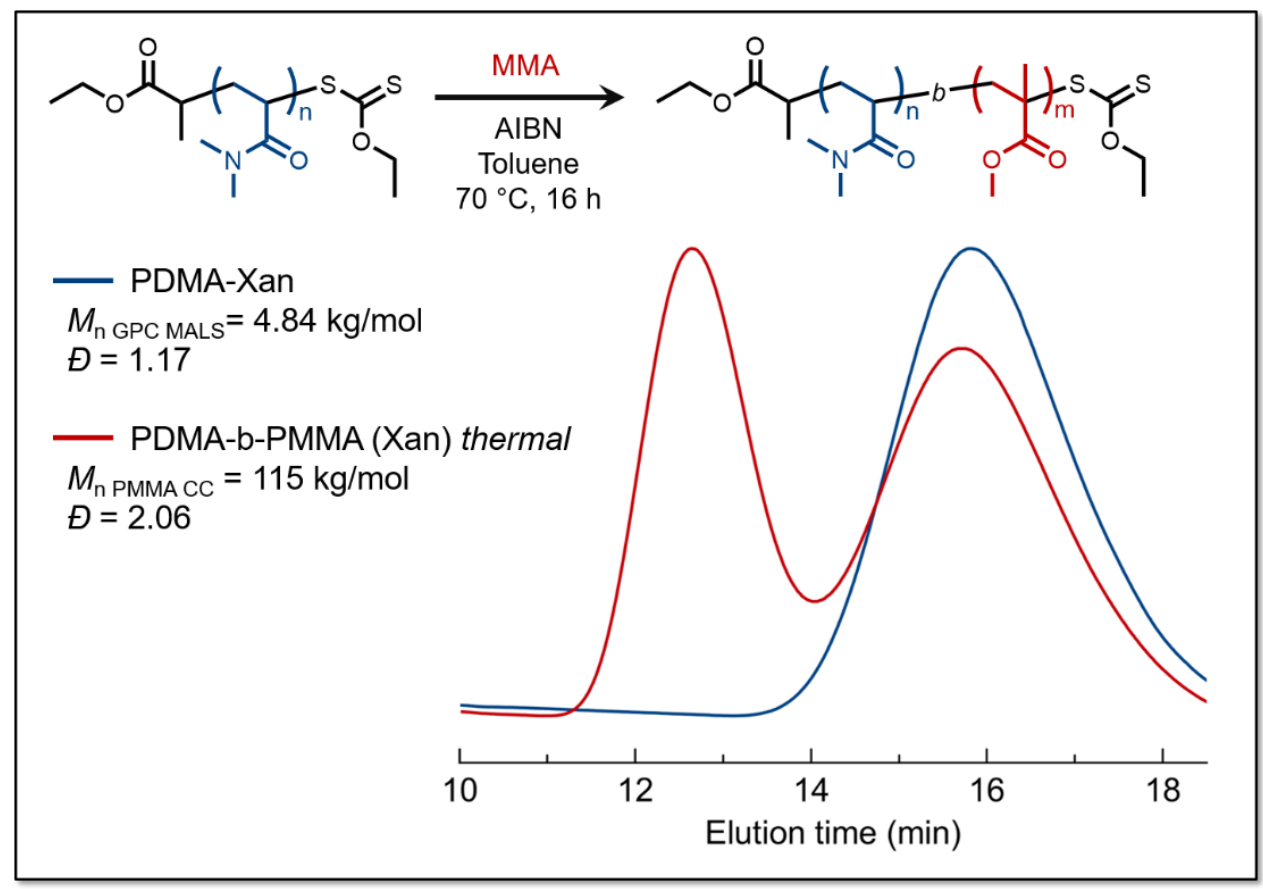

Figure S8. Thermal RAFT chain extension of PDMA-Xan with MMA. 


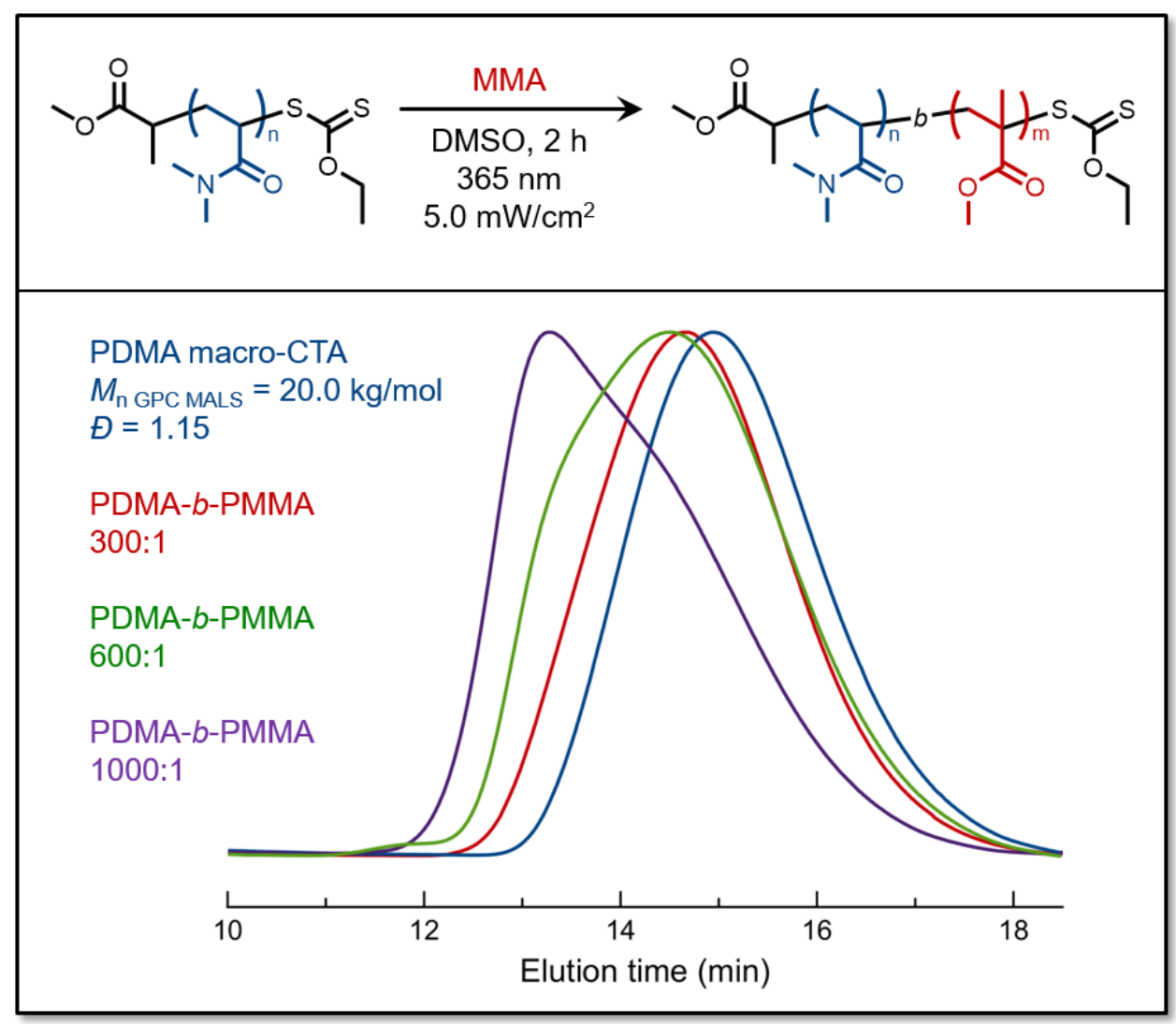

Figure S9. GPC chromatograms of PDMA- $b$-PMMA xanthates targeting various MMA degrees of polymerization. 


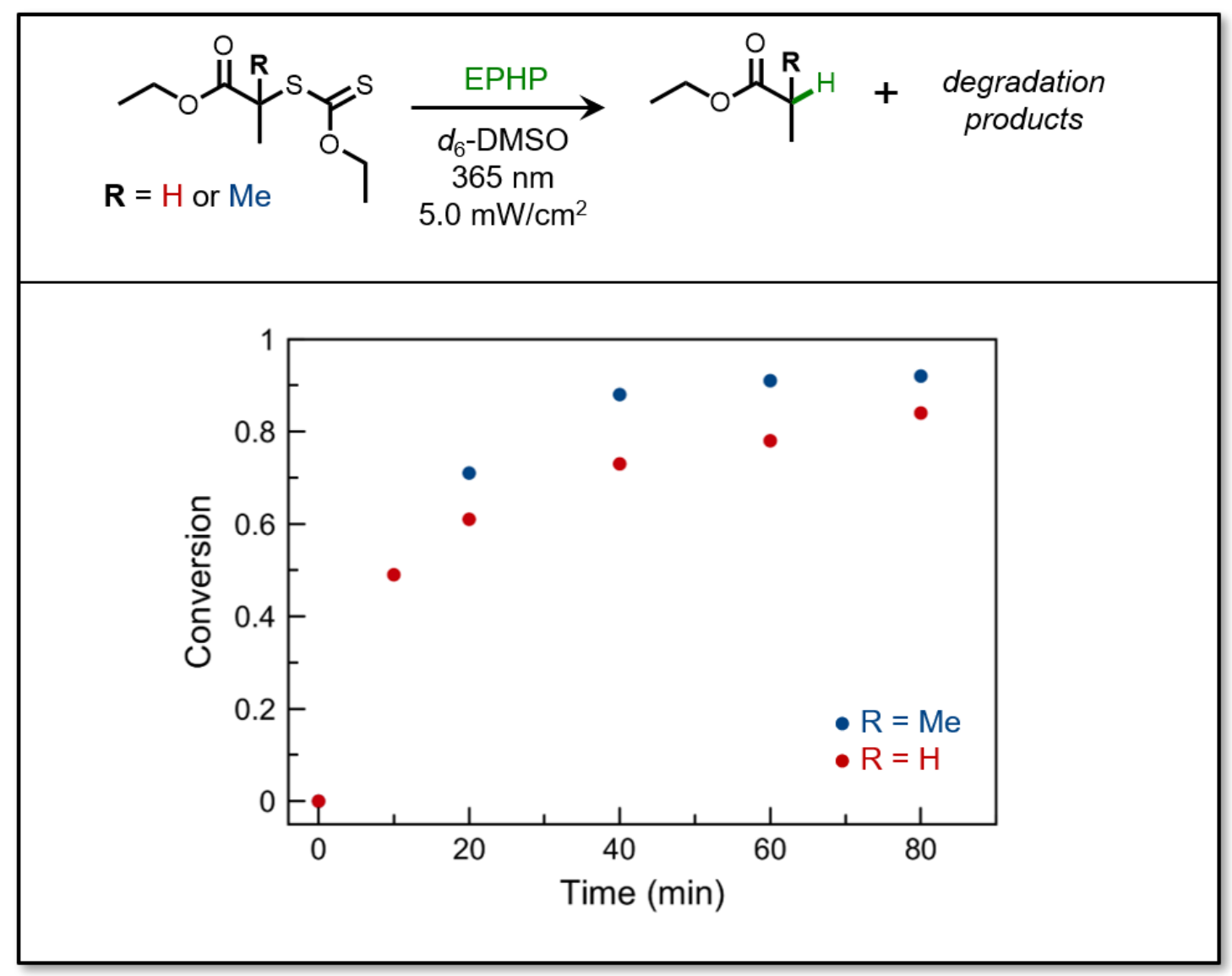

Figure S10. Small molecule photolysis study comparing the relative photolysis rates of acrylic and methacrylic chain ends. 
PDMA macro-CTA

$M_{\mathrm{n} \text { GPC MALS }}=20.0 \mathrm{~kg} / \mathrm{mol}$ $\bigoplus=1.15$

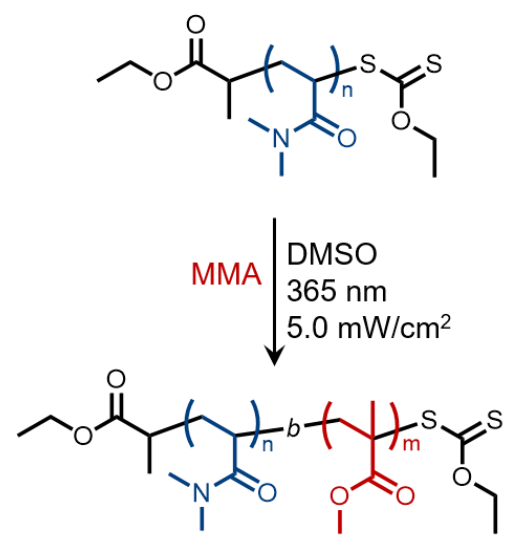

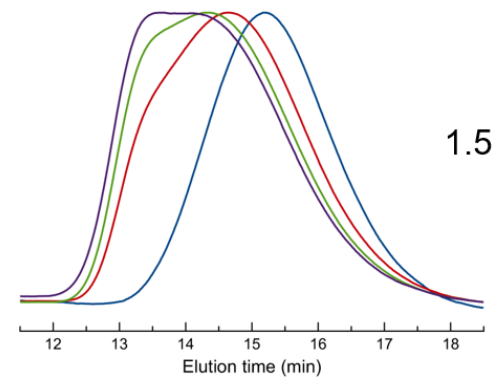

$1.5 \mathrm{M}[\mathrm{MMA}]_{0}$

PDMA- $b-P M M A$

$30 \mathrm{~min}$

$60 \mathrm{~min}$

$90 \mathrm{~min}$

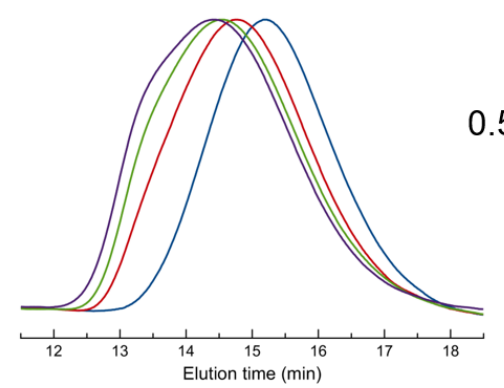

$0.5[\mathrm{MMA}]_{0}$

PDMA- $b$-PMMA

$30 \mathrm{~min}$

$60 \mathrm{~min}$

90 min

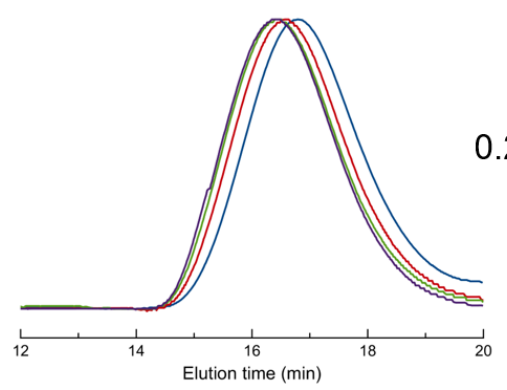

$0.2 \mathrm{M}[\mathrm{MMA}]_{0}$

PDMA-b-PMMA

$30 \mathrm{~min}$

$60 \mathrm{~min}$

$90 \mathrm{~min}$

Figure S11. GPC chromatograms revealing an effect of initial monomer concentration on asymmetric chain growth when targeting a higher MMA degree of polymerization.
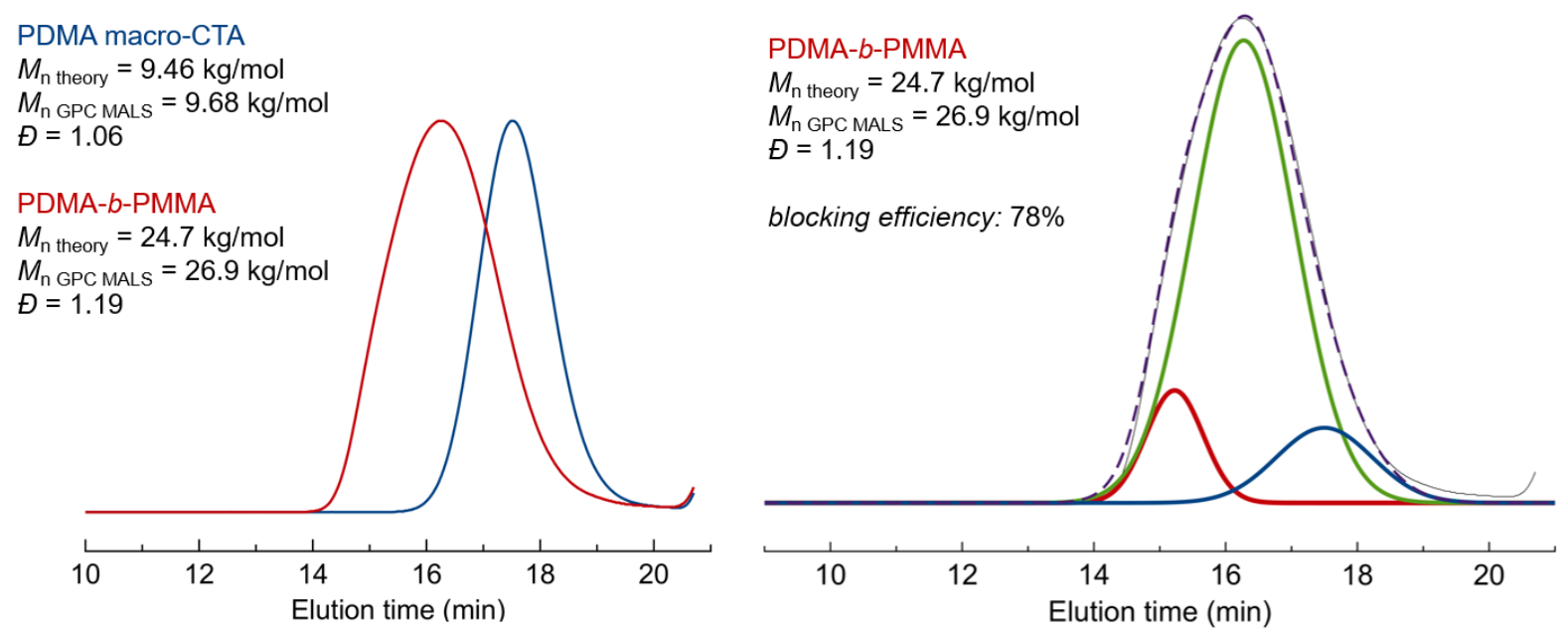

Figure S12. Deconvoluted GPC chromatogram of PDMA- $b$-PMMA (SRA). 


\section{References}

1. Lai, J. T.; Filla, D.; Shea, R., Functional Polymers from Novel Carboxyl-Terminated Trithiocarbonates as Highly Efficient RAFT Agents. Macromolecules 2002, 35, 67546756.

2. Smulders, W.; Monteiro, M. J., Seeded Emulsion Polymerization of Block Copolymer Core-Shell Nanoparticles with Controlled Particle Size and Molecular Weight Distribution Using Xanthate-Based RAFT Polymerization. Macromolecules 2004, 37, 4474-4483.

3. Wood, M. R.; Duncalf, D. J.; Rannard, S. P.; Perrier, S., Selective one-pot synthesis of trithiocarbonates, xanthates, and dithiocarbamates for use in RAFT/MADIX living radical polymerizations. Org. Lett. 2006, 8, 553-6. 